\title{
Basic Ionic Liquid as Catalyst in Synthesis of Dimethyl 4-(2-(2,6-Bis(methoxycarbonyl)pyridine-4-yl)vinyl)pyridine-2, 6-dicarboxylate
}

\author{
Xiaobing Liu $\mathbb{D}^{1},{ }^{1}$ Yulin $\mathrm{Hu}^{2}$ and Wei Fu ${ }^{3}$ \\ ${ }^{1}$ School of Chemistry and Chemical Engineering, Jinggangshan University, Jian 343009, China \\ ${ }^{2}$ College of Materials and Chemical Engineering, China Three Gorges University, Yichang 443002, China \\ ${ }^{3}$ School of Mathematics and Physics, Jinggangshan University, Jian 343009, China \\ Correspondence should be addressed to Xiaobing Liu; xiaobingliu928@126.com
}

Received 2 September 2017; Revised 11 December 2017; Accepted 20 December 2017; Published 21 January 2018

Academic Editor: Vinod Kumar Tiwari

Copyright (c) 2018 Xiaobing Liu et al. This is an open access article distributed under the Creative Commons Attribution License, which permits unrestricted use, distribution, and reproduction in any medium, provided the original work is properly cited.

\begin{abstract}
In the lanthanide complexes with some organic ligands, the use of pyridine-2,6-dicarboxylic acid derivatives as sensitizers was better than using others. In this paper, dimethyl 4-(2-(2,6-bis(methoxycarbonyl)pyridine-4-yl)vinyl)pyridine-2,6-dicarboxylate (DVDPA) was synthesized starting from dimethyl 4-(chloromethyl)pyridine-2,6-dicarboxylate (CMDPA) catalyzed by ionic liquid [bmim $] \mathrm{OH}$. The results indicated that the catalytic system presented the highest catalytic activity in the case of $60^{\circ} \mathrm{C}$ and $40 \mathrm{~min}$ and DVDPA yield of $83 \%$ can be obtained when ionic liquid dosage is $10 \%$ of reactant. The ionic liquid [bmim] OH can be recycled five times without obviously decreasing the catalytic activity after vacuum drying dehydration and the stability of the yield of DVDPA can be maintained.
\end{abstract}

\section{Introduction}

Pyridine dicarboxylic acid derivatives are a kind of important organic ligands, which have rigid conjugated structures and rich coordination forms with the wide application in optical fiber communication system and the time resolution of fluorescence immunoassay [1-4]. The substituted pyridine dicarboxylic acid derivatives of rare earth ions form stable complexes, which have stronger luminescence capability and fluorescence intensity compared with other organic ligand sensitization. Dimethyl 4-(2-(2,6-bis(methoxycarbonyl)pyridine4-yl)vinyl)pyridine-2,6-dicarboxylate (DVDPA) is an intermediate of pyridine dicarboxylic acid derivatives ligands, which was initially synthesized by Wittig condensation reaction based on dimethyl 4-(chloromethyl)pyridine-2,6dicarboxylate (CMDPA) as the raw material [5]. The disadvantage of the process is the using of phosphorus salt catalyst and the complex operation of reaction. In addition, the synthesis of DVDPA has been reported using organic nitrogen alkali as catalyst in aqueous solvent [6], but the catalysts are flammable, explosive, and difficult to reuse.
Therefore, the search for a more environmentally friendly catalyst is still a problem to be solved.

In recent years, ionic liquids, as a green catalyst, are widely used in various organic synthesis reactions because of their environmental friendliness and beneficial reuse. 1-Butyl-3methylimidazolium hydroxide $([\mathrm{bmim}] \mathrm{OH})$ is a kind of basic functionalized ionic liquid and has been successfully used for Knoevenagel condensation reaction [7], Mannich reaction [8], Markovnikov addition reaction [9], Michael addition reaction $[10,11]$, Feist-Benary reaction [12], and cycloaddition reaction [13]. This study attempts to use the basic ionic liquid [bmim] $\mathrm{OH}$ as catalyst for synthesis of DVDPA with CMDPA as the raw material. We found that the catalytic system has good catalytic performance under mild conditions and simple operation.

\section{Materials and Methods}

2.1. General Reagents and Instrumentation. All starting chemicals (AR grade) were purchased from commercial 


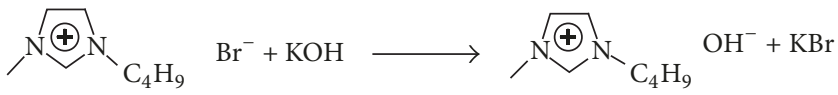

Scheme 1: Preparation of ionic liquid [bmim]OH.

suppliers and used without further purification. Melting points were determined on a Thomas Hoover capillary apparatus and were uncorrected. The IR spectra were recorded with a Bomem-Michelson model 102 FTIR. ${ }^{1} \mathrm{H}$ NMR spectra were recorded on Bruker DRX (500 MHz) spectrometer. Gas chromatography (GC) was recorded on a HP 6890 Plus GC instrument. Elemental analyses were performed on a Yanagimoto MT3CHN recorder.

2.2. Preparation of Ionic Liquid [bmim]OH. Ionic liquid [bmim] $\mathrm{OH}$ was prepared according to [10], as shown in Scheme 1. The dried $\mathrm{CH}_{2} \mathrm{Cl}_{2}(20 \mathrm{ml})$, [bmim]Br $(40 \mathrm{mmol}$, $8.80 \mathrm{~g}$ ), and $\mathrm{KOH}$ ( $40 \mathrm{mmol}, 2.31 \mathrm{~g}$ ) were added to the round bottomed flask at room temperature to react with $10 \mathrm{~h}$. At the end of the reaction, the crude products were filtered and distilled, washed with ether, and dried $10 \mathrm{~h}$ at $90^{\circ} \mathrm{C}$, and the ionic liquid [bmim] $\mathrm{OH}$ was obtained.

2.3. Synthesis of CMDPA. The CMDPA was synthesized according to [5], as shown in Scheme 2. Anhydrous $\mathrm{CHCl} 3(100 \mathrm{~mL})$ and dimethyl 4-(hydroxymethyl)pyridine2,6-dicarboxylate $(6.00 \mathrm{~g}, 26.60 \mathrm{mmol})$ were added to four round bottom flasks at low temperature with magnetic stirring and controlling the reaction temperature of $0-5^{\circ} \mathrm{C}$ under a nitrogen atmosphere. Sulfuryl dichloride (4.80 g, $40.00 \mathrm{mmol}$ ) was added slowly to the mixture, after finishing dropping, TLC tracking reaction, $45 \mathrm{~min}$ vacuum evaporation to eliminate solvent, the crude product with ethyl acetate recrystallization, and vacuum drying pale. Orange yellow solid $(2.76 \mathrm{~g}, 11.10 \mathrm{mmol})$ was obtained, with the melting point 168 to $171^{\circ} \mathrm{C}$ and the yield $86.4 \%$ (IR (KBr), $v / \mathrm{cm}^{-1}$ : 3079, 2959, 2836, 1725, 1710, 1380, 1257, 1125, 798. (EI-MS, $\mathrm{m} / z$, rel., intensity): $243\left(\mathrm{M}^{+}\right), 213\left(\mathrm{M}, \mathrm{OCH}_{3}, 62 \%\right), 184(\mathrm{M}-$ $\left.\mathrm{OCH}_{3}-\mathrm{CO}, 100 \%\right) ;{ }^{1} \mathrm{H} \mathrm{NMR}\left(400 \mathrm{MHz}, \mathrm{CDCl}_{3}\right.$ ) $\delta: 8.27$ (s, $2 \mathrm{H}, \mathrm{Py}, \mathrm{H}), 4.45$ (s, 2H, $\left.\mathrm{CH}_{2} \mathrm{Cl}\right), 4.06\left(\mathrm{~s}, 6 \mathrm{H}, \mathrm{OCH}_{3}\right)$ ).

2.4. Synthesis of DVDPA Catalyzed by [bmim]OH. The synthesis of DVDPA was shown as Scheme 3. CMDPA (6.1 g, $25 \mathrm{mmol})$ was dissolved in THF $(60 \mathrm{~mL})$ and to this mixture $0.5 \mathrm{~g}$ [bmim] $\mathrm{OH}$ dissolved in methanol $(40 \mathrm{~mL})$ was added. The mixture was stirred for $10 \mathrm{~min}$ and then was heated to $60^{\circ} \mathrm{C}$ with stirring for $40 \mathrm{~min}$. The reaction mixture was cooled to $10^{\circ} \mathrm{C}$ and was allowed to stand for about $30 \mathrm{~min}$; then it was filtered. The collected solid was recrystallized from methanol to give $4.3 \mathrm{~g}(83 \%)$ of DVDPA as a whitish solid (mp 191-193 ${ }^{\circ} \mathrm{C}$ (lit. [6] mp 192-194 ${ }^{\circ} \mathrm{C}$ ). IR (KBr), $v / \mathrm{cm}^{-1}: 3415$, 2918, 1734, 1636, 1593, 1437, 1390, 1228, 1000, 911, 773, 696. ${ }^{1} \mathrm{H}$ NMR $\left(\mathrm{CDCl}_{3}\right), \delta: 8.13(\mathrm{~s}, 4 \mathrm{H}, \mathrm{Py}-\mathrm{H}), 7.16-7.53(\mathrm{~d}, 2 \mathrm{H}, J=$ $16.0 \mathrm{~Hz}, \mathrm{Py}-\mathrm{CH}=), 4.04\left(\mathrm{~s}, 6 \mathrm{H}, \mathrm{OCH}_{3}\right)$. EA (calculated for $\mathrm{C}_{20} \mathrm{H}_{18} \mathrm{~N}_{2} \mathrm{O}_{8}$ ): \% C 57.36 (57.97), H 4.68 (4.35), N 6.32 (6.76)). The filtrate with ionic liquid was reused after vacuum drying.
TABLE 1: Effects of [bmim]OH/solvent on the synthesis of DVDPA.

\begin{tabular}{lcc}
\hline Entry & Catalyst/solvent & Yield $(\%)^{\mathrm{b}}$ \\
\hline$(1)$ & {$[\mathrm{bmim}] \mathrm{OH} / \mathrm{H}_{2} \mathrm{O}$} & 62 \\
$(2)$ & {$[\mathrm{bmim}] \mathrm{OH} / \mathrm{CH}_{3} \mathrm{OH}$} & 83 \\
$(3)$ & {$[\mathrm{bmim}] \mathrm{OH} / \mathrm{CH}_{3} \mathrm{CN}$} & 80 \\
$(4)$ & {$[\mathrm{bmim}] \mathrm{OH} / \mathrm{CH}_{2} \mathrm{Cl}_{2}$} & 71 \\
$(5)$ & {$[\mathrm{bmim}] \mathrm{OH} / \mathrm{None}$} & 60 \\
\hline
\end{tabular}

Reaction conditions: CMDPA $(25 \mathrm{mmol})$, tetrahydrofuran $60 \mathrm{ml}$, [bmim $] \mathrm{OH}(2.5 \mathrm{mmol}), 60^{\circ} \mathrm{C}, 40 \mathrm{~min} .{ }^{\mathrm{b}}$ Isolated yield.

TABLE 2: Effects of reaction temperature on the reaction.

\begin{tabular}{lcc}
\hline Entry & Temperature $/{ }^{\circ} \mathrm{C}$ & Yield $(\%)^{\mathrm{b}}$ \\
\hline$(1)$ & 30 & 42 \\
$(2)$ & 40 & 64 \\
$(3)$ & 50 & 78 \\
$(4)$ & 60 & 83 \\
$(5)$ & 70 & 81 \\
$(6)$ & 80 & 82 \\
$(7)$ & 90 & 79 \\
$(8)$ & 100 & 71 \\
\hline
\end{tabular}

Reaction conditions: CMDPA $(25 \mathrm{mmol})$, tetrahydrofuran $60 \mathrm{ml}$, [bmim] OH (2.5 mmol), $\mathrm{CH}_{3} \mathrm{OH}(40 \mathrm{ml}), 40 \mathrm{~min}$. ${ }^{\mathrm{b}}$ Isolated yield.

\section{Results and Discussion}

In the initial catalytic activity experiments, different solvents were screened for the synthesis of DVDPA. The results are summarized in Table 1 . As shown in Table 1 , the reaction could proceed effectively in polar organic solvents, for example, methanol and acetonitrile (entries (2) and (3)). Without solvent, the system will become mushy as the reaction proceeds, while, using water as a solvent, it is difficult to handle the mixture after reaction. Therefore, methanol was used as the solvent for further research.

Next, we investigated the effect of reaction temperature on the yield of the DVDPA, as shown in Table 2. As shown in Table 2, it indicates that, in the catalytic system of [bmin] $\mathrm{OH}$, the yield of DVDPA increased with the reaction temperature increasing. The optimum reaction temperature is $60^{\circ} \mathrm{C}$ (entry (4)), and increasing the reaction temperature beyond this led to no substantial improvement in the yield. The reason why the yield of targeted product decreased when increasing the temperature may be higher temperature being not favorable for the condensation reaction.

Subsequently, we investigated the effect of reaction time on the reaction, as shown in Figure 1 . In the [bmin] $\mathrm{OH}$ catalytic system, with the increase of reaction time, the yield of the product increased gradually. When the reaction time was $40 \mathrm{~min}$, the yield was the highest, and then the reaction time prolonged, and the yield was no longer increased. So the reaction time under the conditions should be $40 \mathrm{~min}$.

The effect of the amount of ionic liquid [bmim] OH on the reaction was screened as shown in Table 3 . The results showed that no desirable product could be detected when the reaction proceeded without any catalyst (entry (1)), which 
<smiles>COC(=O)c1cc(CCl)cc(C(=O)OC)n1</smiles>

SCHEME 2: Synthesis of CMDPA.<smiles>COC(=O)c1cc(CCl)cc(C(=O)OC)n1</smiles><smiles>COC(=O)c1cc(/C=C/c2cc(C(C)=O)nc(C(=O)OC)c2)cc(C(C)=O)n1</smiles>

Scheme 3: Synthesis of DVDPA.

TABLE 3: Effect of the amount of ionic liquid [bmim] $\mathrm{OH}$ on the reaction.

\begin{tabular}{lcc}
\hline Entry & Catalyst $(\mathrm{mmol})$ & Yield $(\%)^{\mathrm{b}}$ \\
\hline$(1)$ & 0 & 0 \\
$(2)$ & 1.0 & 68 \\
$(3)$ & 1.5 & 76 \\
$(4)$ & 2.0 & 81 \\
$(5)$ & 2.5 & 83 \\
$(6)$ & 3.0 & 83 \\
\hline
\end{tabular}

Reaction conditions: CMDPA $(25 \mathrm{mmol})$, tetrahydrofuran $60 \mathrm{ml}, \mathrm{CH}_{3} \mathrm{OH}$ $(40 \mathrm{ml}), 60^{\circ} \mathrm{C}, 40 \mathrm{~min} .{ }^{\mathrm{b}}$ Isolated yield.

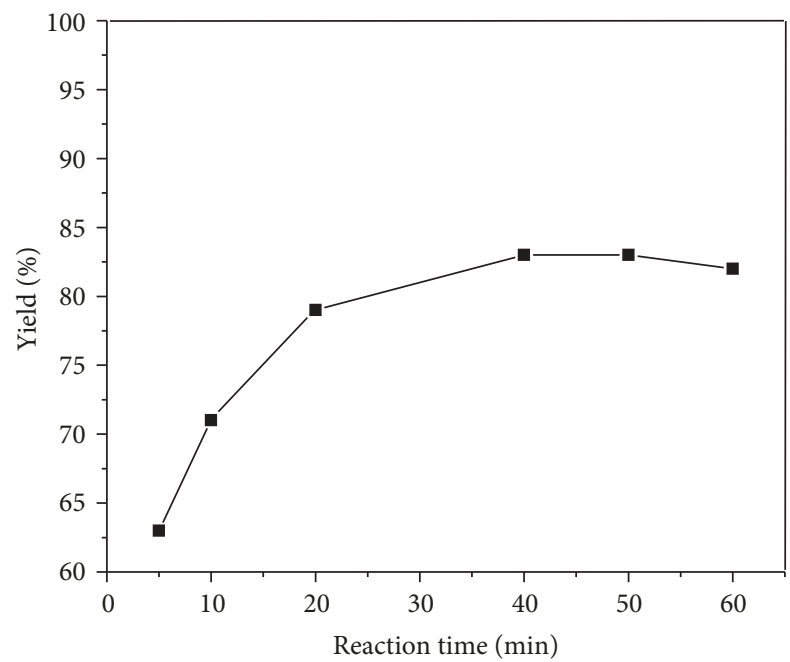

FIGURE 1: Effect of reaction time on reaction. Reaction conditions: CMDPA (25 mmol), tetrahydrofuran $60 \mathrm{ml}$, [bmim] OH $(2.5 \mathrm{mmol})$, $\mathrm{CH}_{3} \mathrm{OH}(40 \mathrm{ml}), 60^{\circ} \mathrm{C}$. Isolated yield.

indicated that the catalyst should be absolutely necessary for the reaction. With the amount of [bmim] OH increased, a ramp in the yield was clearly observed. The optimum amount of [bmim] OH was $2.5 \mathrm{mmol}$ (10\% based on CMDPA) (entry (5)), and increasing the amount of catalyst beyond this led to no substantial improvement in the yield.

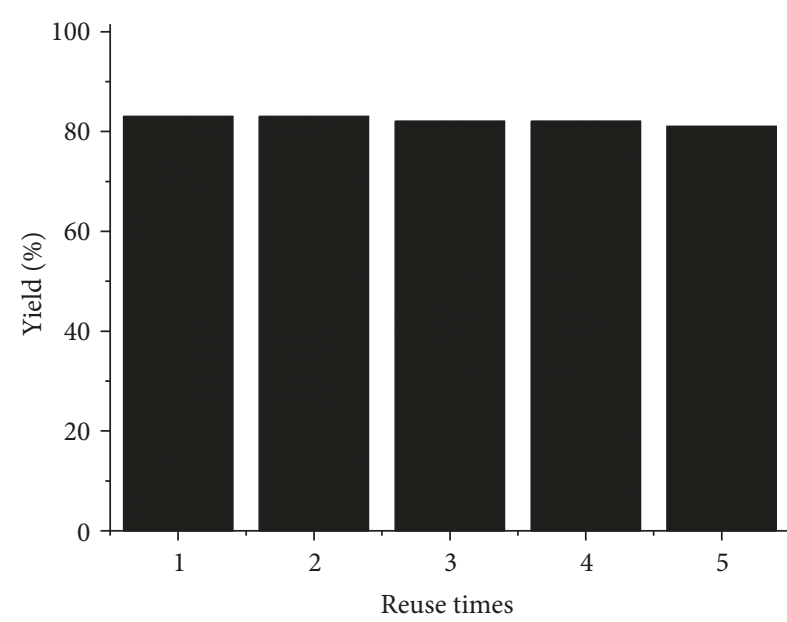

Figure 2: Reusability of ionic liquid [bmim] OH.

Compared with traditional solvents and catalysts, ionic liquids are easily reused, which is superior to the conventional solvents and catalysts. When optimizing the reaction condition, the recycling performance of [bmim] $\mathrm{OH}$ in the reaction was investigated. As shown in Figure 2, the catalyst could be reused at least five times without significant decrease in catalytic activity. The yield of the target product DVDPA is above $80 \%$.

\section{Conclusions}

In conclusion, dimethyl 4-(2-(2,6-bis(methoxycarbonyl) pyridine-4-yl)vinyl)pyridine-2,6-dicarboxylate (DVDPA) was synthesized starting from dimethyl 4-(chloromethyl) pyridine-2,6-dicarboxylate (CMDPA) catalyzed by ionic liquid $[\mathrm{bmim}] \mathrm{OH}$. The results indicated that the catalytic system presented the highest catalytic activity in the case of $60^{\circ} \mathrm{C}$ and $40 \mathrm{~min}$ and DVDPA yield of $83 \%$ can be obtained when ionic liquid dosage is $10 \%$ of reactant. The ionic liquid [bmim] $\mathrm{OH}$ can be recycled for five times without obviously decreasing the catalytic activity after vacuum drying dehydration and the stability of the yield of DVDPA can be maintained. 


\section{Conflicts of Interest}

All authors declare no conflicts of interest.

\section{Acknowledgments}

This research was supported by the Doctoral Foundation of Jinggangshan University (Grant no. JZB1322).

\section{References}

[1] R. R. Tang, Z. E. Yan, C. C. Guo, and Y. M. Luo, "Synthesis of $\mathrm{Eu}$ (III) and $\mathrm{Tb}$ (III) complexes with novel pyridine-2, 6dicarboxylic acid derivatives and their fluorescence properties," Chemical Journal of Chinese Universities, vol. 27, no. 3, pp. 472477, 2006.

[2] J. T. Groves and I. O. Kady, "Sequence-specific cleavage of DNA by oligonucleotide-bound metal complexes," Inorganic Chemistry, vol. 32, no. 18, pp. 3868-3872, 1993.

[3] J. B. Lamture and T. G. Wensel, "A novel reagent for labelling macromolecules with intensely luminescent lanthanide complexes," Tetrahedron Letters, vol. 34, no. 26, pp. 4141-4144, 1993.

[4] P.V. Chouthaiwale, S. Lapointe, and F. Tanaka, "Synthesis of 4-substituted-pyridine-2,6-dicarboxylic acid derivatives from pyruvates and aldehydes in one pot," Heterocycles, vol. 95, no. 1, pp. 587-594, 2017.

[5] G.-L. Gu, R.-R. Tang, Y.-H. Zheng, and X.-M. Shi, "Synthesis, characterization and fluorescence properties of novel pyridine dicarboxylic acid derivatives and corresponding $\mathrm{Tb}$ (III) complexes," Spectrochimica Acta Part A: Molecular and Biomolecular Spectroscopy, vol. 71, no. 1, pp. 209-214, 2008.

[6] G.-L. Gu, M. Lu, and R.-R. Tang, "Application of wittig reaction in synthesis of novel pyridine dicarboxylic acid derivatives with high ligand activity," Synthetic Communications, vol. 41, no. 22, pp. 3403-3408, 2011.

[7] K. Gong, D. Fang, Q. R. Shi, and Z. L. Liu, "Knoevenagel condensation reaction catalyzed by functionalized ionic liquid," Chinese Journal of Applied Chemistry, vol. 24, no. 9, pp. 10891091, 2007.

[8] K. Gong, D. Fang, Q.-R. Shi, and Z.-L. Liu, "Mannich reaction catalyzed by basic functionalized ionic liquid," Chinese Journal of Energetic Materials, vol. 16, no. 2, pp. 121-124, 2008.

[9] J.-M. Xu, B.-K. Liu, W.-B. Wu, C. Qian, Q. Wu, and X.-F. Lin, "Basic ionic liquid as catalysis and reaction medium: a novel and green protocol for the Markovnikov addition of N-heterocycles to vinyl esters, using a task-specific ionic liquid, [bmIm] OH," The Journal of Organic Chemistry, vol. 71, no. 10, pp. 3991-3993, 2006.

[10] B. C. Ranu and S. Banerjee, "Ionic liquid as catalyst and reaction medium. The dramatic influence of a task-specific ionic liquid, [bmim] $\mathrm{OH}$, in Michael addition of active methylene compounds to conjugated ketones, carboxylic esters, and nitriles," Organic Letters, vol. 7, no. 14, pp. 3049-3052, 2005.

[11] B. C. Ranu, S. Banerjee, and R. Jana, "Ionic liquid as catalyst and solvent: the remarkable effect of a basic ionic liquid, [bmim] $\mathrm{OH}$ on Michael addition and alkylation of active methylene compounds," Tetrahedron, vol. 63, no. 3, pp. 776-782, 2007.

[12] B. C. Ranu, L. Adak, and S. Banerjee, "Ionic liquid promoted interrupted Feist-Benary reaction with high diastereoselectivity," Tetrahedron Letters, vol. 49, no. 31, pp. 4613-4617, 2008.
[13] A. A. Ali, M. Konwar, M. Chetia, and D. Sarma, "[Bmim]OH mediated $\mathrm{Cu}$-catalyzed azide-alkyne cycloaddition reaction: a potential green route to 1,4-disubstituted 1,2,3-triazoles," Tetrahedron Letters, vol. 57, no. 50, pp. 5661-5665, 2016. 

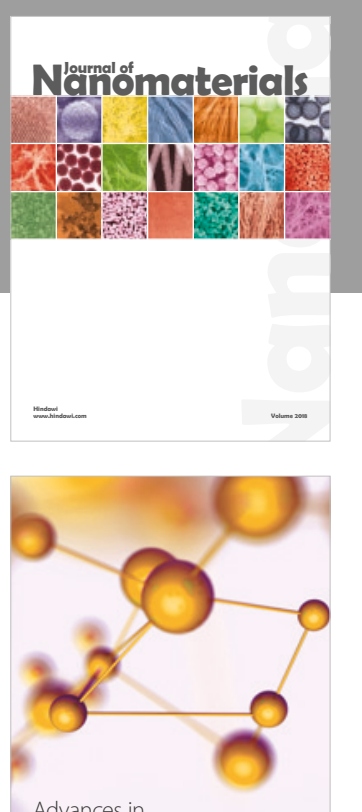

Physical Chemistry
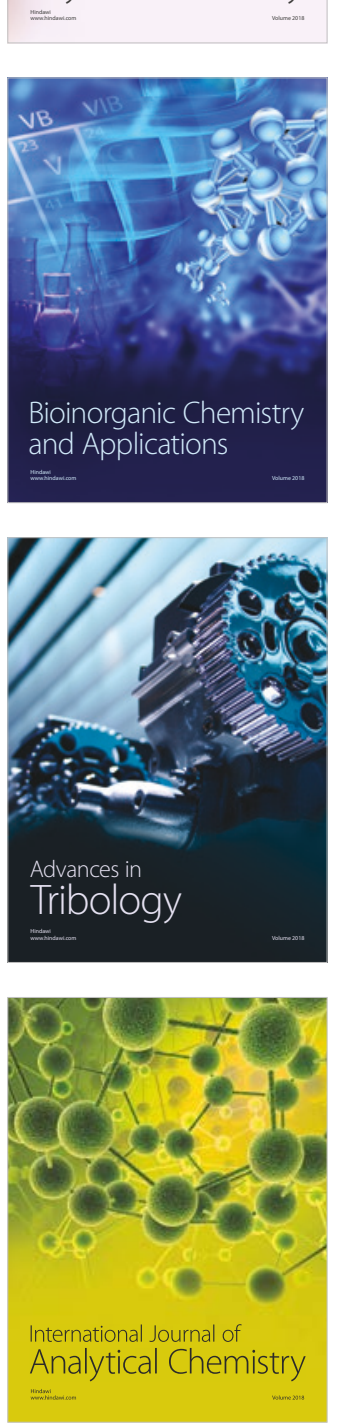

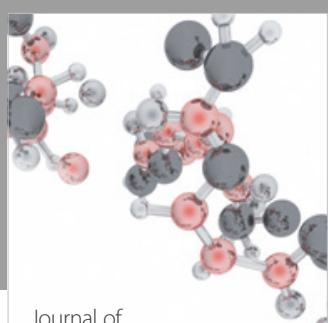

Analytical Methods

in Chemistry

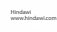

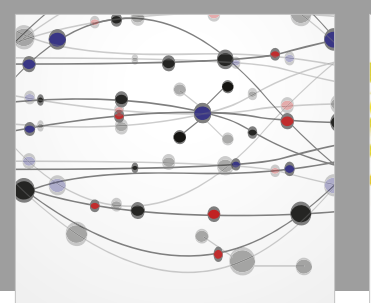

The Scientific World Journal

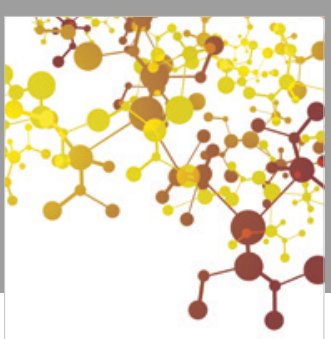

Journal of

Applied Chemistry
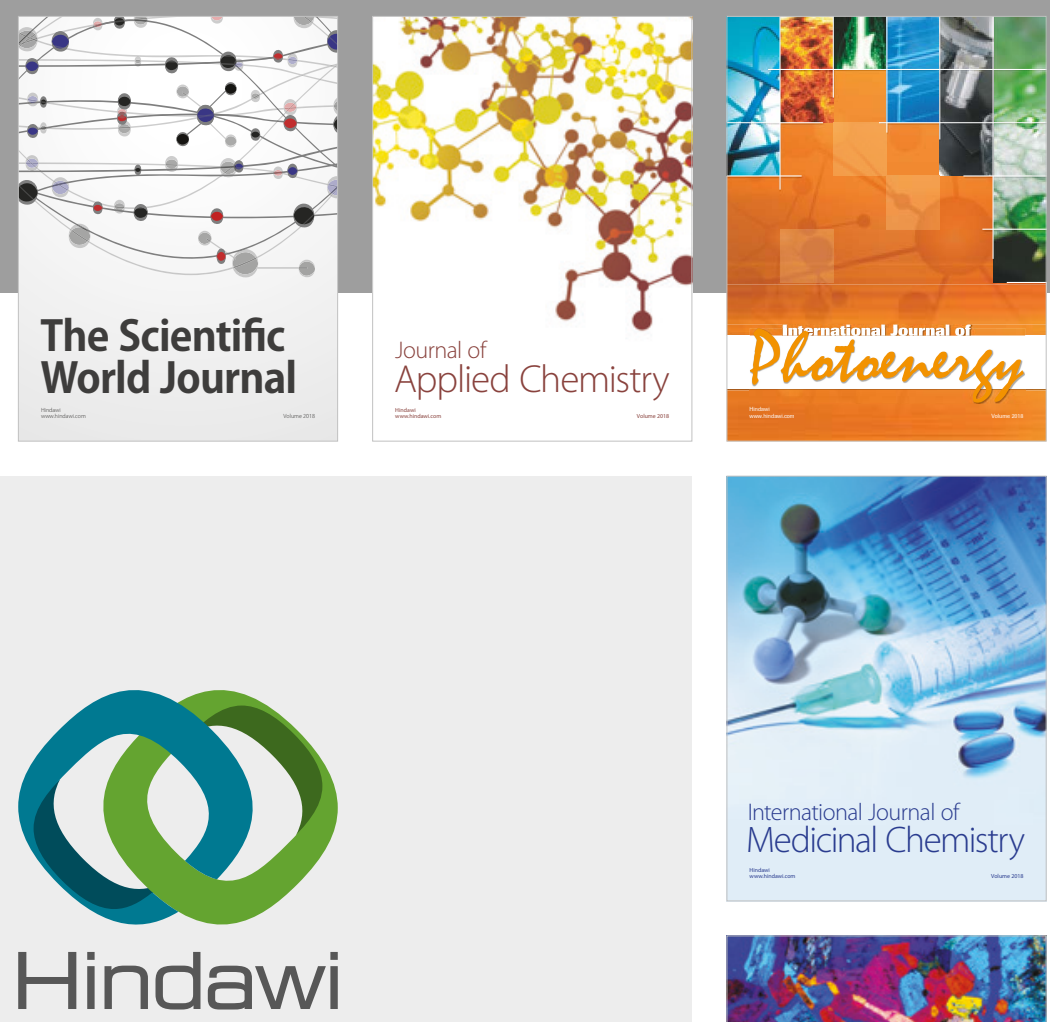

Submit your manuscripts at

www.hindawi.com
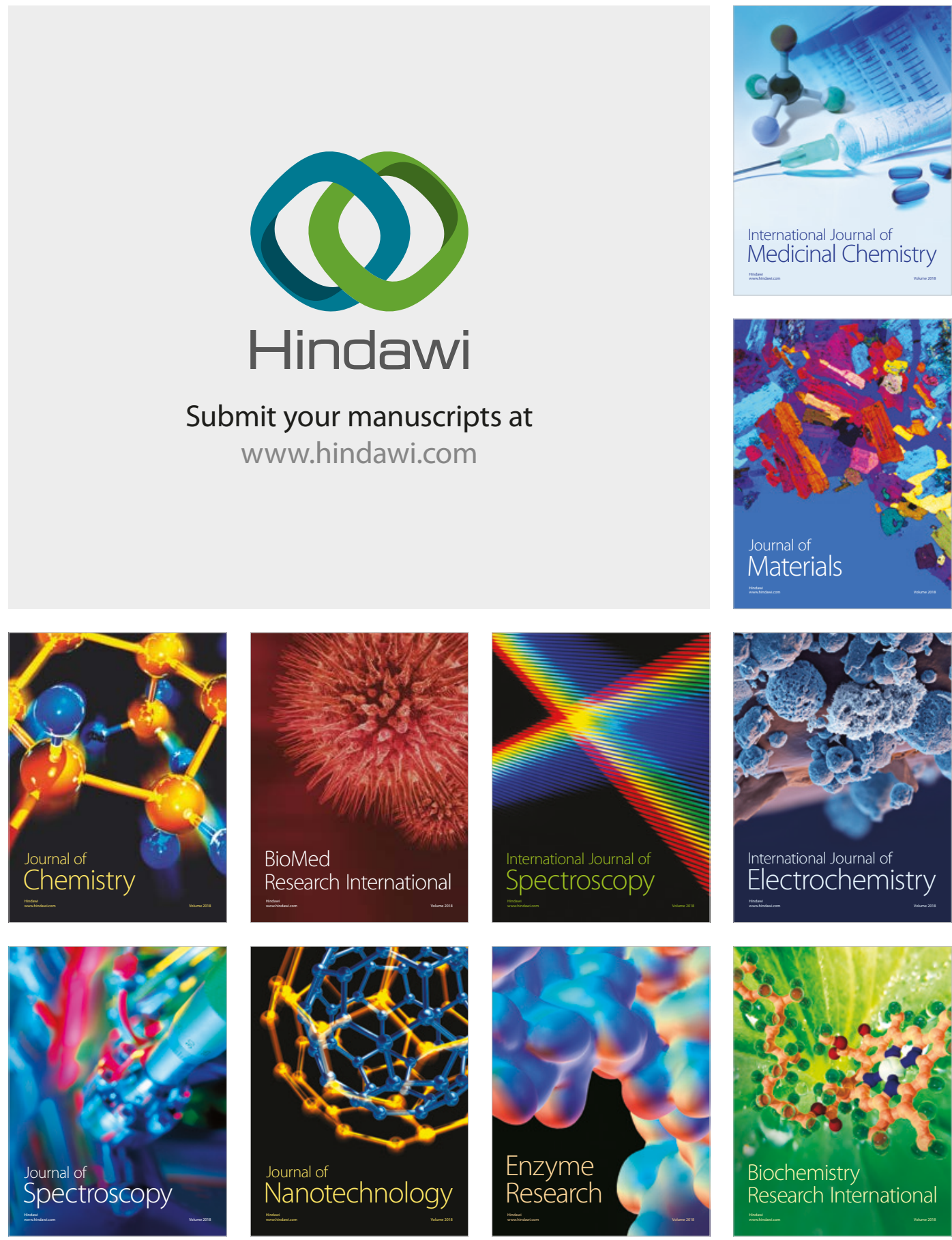
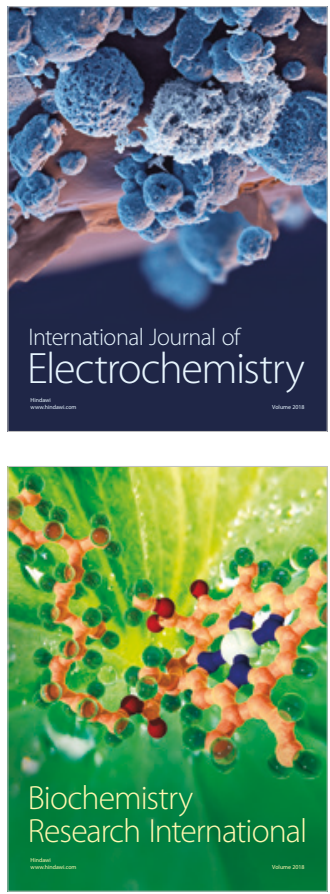